\title{
Pengaruh pembelajaran inquiry argumentatif terhadap pemahaman konsep siswa kelas X MIA SMA Negeri 3 Malang pada pokok bahasan pembiasan cahaya \\ Esa Chory Rizky Ananda, Sutopo*, Purbo Suwasono
}

Universitas Negeri Malang, Jl. Semarang No. 5 Malang, Jawa Timur, Indonesia

*Penulis korespondensi, Surel: sutopo.fisika@um.ac.id

Paper received: 01-08-2021; revised: 15-08-2021; accepted: 31-08-2021

\begin{abstract}
Abstrak
Penelitian pembelajaran ini bertujuan untuk meningkatkan kemampuan pemahaman konsep siswa pada subbab pembiasan cahaya melalui model pembelajaran Inquiry Argumentatif. Penelitian ini termasuk jenis penelitian mixed method jenis embedded design, yaitu dengan menggunakan gabungan metode kuantitatif dan kualitatif. Hasil penelitian menunjukkan adanya peningkatan pemahaman konsep siswa setelah mengikuti pembelajaran dengan menggunakan model pembelajaran Inquiry argumentatif. Peningkatan rata-rata pemahaman konsep siswa pada materi pembiasan pada cahaya sebesar 29,2 persen.
\end{abstract}

Kata kunci: inkuiri argumentatif; kemampuan pemahaman konsep

\section{Pendahuluan}

Kurangnya pemahaman konsep siswa pada materi optik disebabkan karena pengetahuan awal siswa yang salah dan kurangnya keterampilan proses siswa dalam pembelajaran (Debnath, dkk., 2012; Elianawati \& Wahyuni, 2010; Prihatiningtyas, dkk, 2013; Widayanto, 2009; Saeed, 2013). Kurangnya pemahaman konsep siswa muncul pada konsep sifat-sifat cahaya, pemantulan, pembiasan, pembentukan bayangan pada cermin dan lensa, (Aydin, dkk, 2004; Suniati, dkk, 2013; Elianawati \& Wahyuni, 2010). Pemahaman konsep sangatlah penting untuk mencapai kompetensi dasar pada materi optika, karena tanpa adanya pemahaman konsep yang baik maka siswa akan kesulitan menganalisis cara kerja alat optik. Dalam pembelajaran, perlu adanya konsep yang matang agar dapat menghasilkan pemahaman konsep yang baik.

Kurikulum 2013 menuntut agar pembelajaran yang dilakukan bermakna dan siswa diharapkan dapat menguasai konsep dengan baik. Untuk mencapai tuntukan kurikulum 2013 diperlukan adanya keaktifan siswa dalam kegiatan pembelajaran agar terjadi peningkatan pemahaman konsep siswa (Saeed, 2013). Kemampuan pemahaman konsep siswa juga bisa ditingkatkan dengan cara siswa dilatih untuk berargumentasi (Osborne, 2010). Apabila siswa sudah memiliki pemahaman konsep yang matang, maka siswa dengan mudah menganalisis cara kerja alat optik. Perlu adanya suatu inovasi pembelajaran yang dapat meningkatkan pemahaman konsep siswa dan mengacu pada kurikulum 2013.

Inquiry argumentatif merupakan salah satu model pembelajaran yang cocok untuk mencapai KD 3.9, terutama pada sub bahasan penguasaan konsep pada pembiasan cahaya. Pembelajaran yang dilakukan sesuai dengan syntax (tahapan) pembelajaran inkuiri, yaitu:observation, manipulation, generalization, verification, application (Wenning, 2010). Setiap tahapan dalam pembelajaran siswa dituntut agar dapat berargumentasi dengan semaksimal mungkin. 
Manfaat dari penelitian ini adalah sebagai salah satu alternatif pembelajaran fisika di sekolah agar pembelajaran fisika lebih bermakna. Selain itu juga guru dapat mengetahui kemampuan awal siswa melalui pertanyaan-pertanyaan atau pretest.

\section{Metode}

Penelitian menggunakan gabungan metode kuantitatif dan kualitatf (mixed method) jenis embedded design (Creswell, 2012). Data kuantitatif digunakan untuk mengetahui pengaruh pembelajaran inkuiri terhadap pemahaman konsep siswa tentang optik, sedangkan data kualitatif digunakan untuk memaparkan kegiatan siswa selama pembelajaran.

Penelitian ini dilakukan dalam 6 tahapan, mulai dari tahapan untuk mengetahui kemampuan awal siswa, hingga tahapan kesimpulan. Berikut tahapan-tahapan pelaksanaan penelitian (Gambar 1)

Gambar 1 Tahap-tahap Pelaksanaan Penelitian Mixed Method dengan Embedded Experimental Model

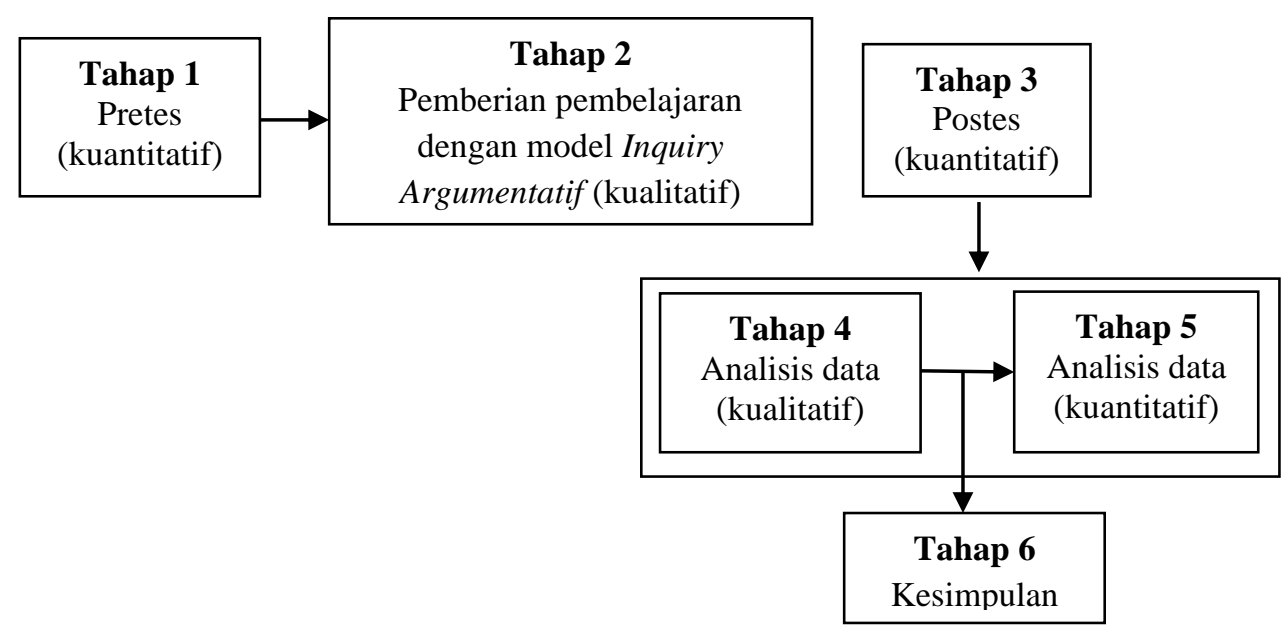

Penelitian diawali dengan pemberian pretes untuk mengetahui kemampuan awal siswa pada materi optik. Soal pretest yang dikerjakan siswa berupa 7 soal pilihan ganda dan 2 soal essay. Tahap kedua adalah implementasi pembelajaran pembiasan cahaya dengan menggunakan model pembelajaran Inqiury Argumentatif. Tahapan dalam pembelajaran inkuiri adalah observation (siswa mengamati fenomena dan kemudian memberikan respon terhadap fenomena tersebut), manipulation (siswa melakukan penyelidikan yang berkaitan dengan fenomena, mengumpulkan dan mengolah data kualitatif maupun kuantitatif), generalitation (siswa membuat kesimpulan dan menemukan konsep baruberdasarkan hasil penyelidikan), verification (siswa mempresentasikan hasil penyelidian kepada kelompok lain untuk diperiksa dan ditanggapi), dan application (siswa mengaplikasikan apa yang telah diperolehnya dalam situasi baru). Selama tahap pembelajaran dilakukan observasi lapangan dengan tujuan untuk mengetahui kegiatan yang dilakukan oleh guru dan siswa. Data observasi tersebut digunakan untuk analisis kualitatif dalam pembelajaran.

Tahap ketiga dalam penelitian adalah melakukan posttest, hal ini digunakan dengan tujuan untuk mengetahui pemahaman konsep siswa setelah mengikuti pembelajaran. Soal yang digunakan ketika posttest sama dengan soal pretest. Hasil pretes dan postes dianalisis secara kuantitatif dengan menggunakan analisis deskriptif, uji beda, $d$-effect size dan $\mathrm{N}$-gain. 
Data kualitatif dianalisis dengan cara mendeskripsikan tiap topik pembelajaran yang dilakukan. Dari hasil analisis kemudian data dikaitkan antara kualitatif dan kuantitatif, selanjutnya didapatkan kesimpulan sesuai dengan rumusan masalah penelitian.

\section{Hasil dan Pembahasan}

Hasil penelitian dipaparkan dengan 2 data, yaitu seara kualitatif dan kuantitatif. Penelititan ini membahas dua sub topik, yaitu (1) Pembiasan pada Bidang Datar dan (2) Pembiasan pada Lensa. Berikut paparan hasil penelitian secara kualitatif:

Setelah poembelajaran pada sub topik pertama siswa telah memahami pembiasan pada bidang datar dan siswa dapat mengaplikasikan hukum pembiasan Snellius untuk menghitung sudut bias. Kesulitan yang dialami siswa sub topik ini yaitu memahami konsep pemantulan sempurna. Hal ini terlihat dari analisis LKS yang dikerjka siswa. siswa menganggap semua sinar yang datang ke suatu medium akan mengalami pembiasan seutuhna, padahal pada kenyataannya sinar tetap mengalami pemantulan.

Setelah pembelajaran pada sub topik kedua siswa memahami konsep pembiasan pada lensa cembung dan cekung, serta aplikasinya dalam kehidupan sehari-hari. dalam pembelajaran ini juga diketahui siswa dapat menggambarkan hasil bayangan dari lensa cembung beserta sifat bayangannya. Siswa lebih sering menggunakan teorema ruang untuk mencari sifat bayagan yang terjadi. Hal ini terbukti ketika guru menghadirkan soal yang bertujuan untuk mengetahui sifat bayangan yang dihasilkan oleh lensa cekung ketika benda berada di ruang II. Kebanyakan siswa menjawab hasil bayangannya adalah maya, tegak, diperbesar. Pada kenyataannya jawaban yang dipaparkan siswa tersebut salah, karena pada lensa cekung tidak berlaku teorema ruang untuk mengetahui sifat bayangan.

Selanjutnya dilakukan analisis kuantitatif. Analisis kuantitatif dilakukan dengan tujuan agar dapat mengetahui seberapa besar peningkatan kemampuan pemahaman konsep siswa pada materi optik. Data kemampuan pemahaman konsep siswa didapatkan dari nilai pretest dan posttest siswa. Nilai pretest digunakan untuk mengukur kemampuan awal siswa, sedangkan posttest digunakan untuk mengukur pemahaman konsep siswa. Berikut hasil pretest dan posttet siswa (Gambar 2).

\section{Gambar 2 Diagram Rata-rata Nilai Siswa pada Setiap Butir Soal}

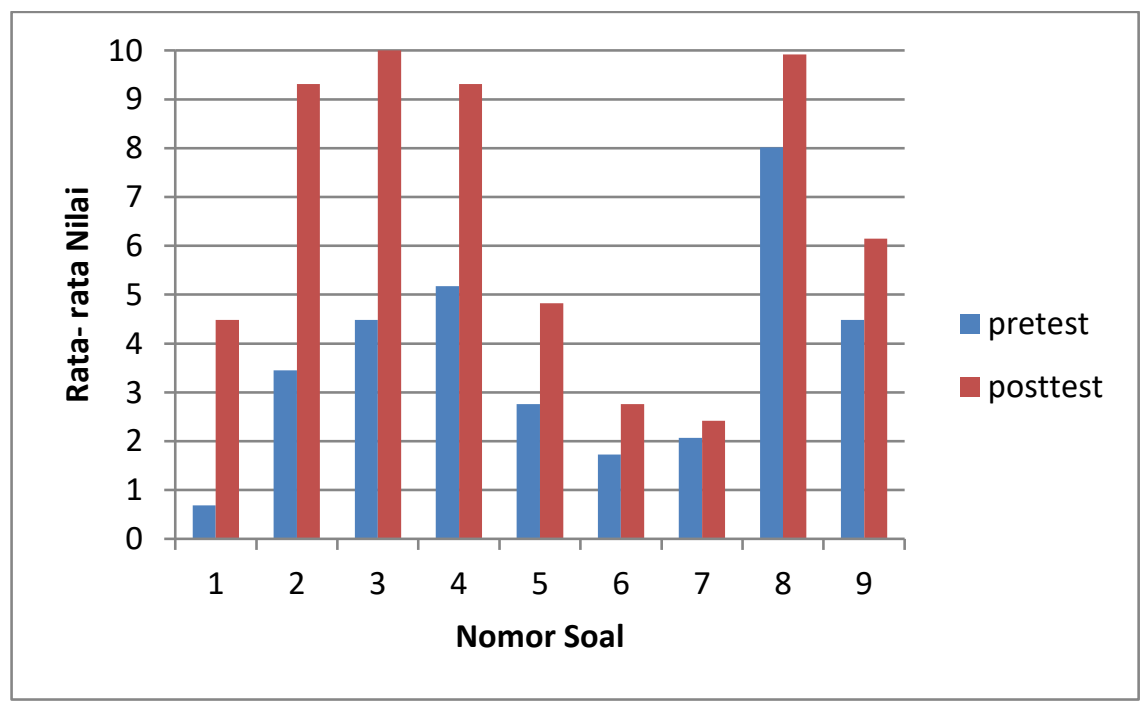


Berdasarkan hasil pretest dan posttest menunjukkan adanya peningkatan skor ratarata siswa tiap butir soal. Skor hasil pretest dan posttest siswa juga dianalisis dengan menggunakan perhitungan statistik deskriptif menggunakan SPSS (tabel 1).

\section{Tabel 1 Descriptive Statistics}

\begin{tabular}{|l|l|l|l|l|c|c|c|c|}
\hline & \multicolumn{1}{|c|}{$\mathrm{N}$} & Minimum & Maximum & \multicolumn{1}{c|}{ Sum } & Mean & Std. Deviation & \multicolumn{2}{|c|}{ Skewness } \\
\hline & Statistic & Statistic & Statistic & Statistic & Statistic & Statistic & Statistic & Std. Error \\
\hline Pretest & 29 & 9.0 & 70.0 & 953.0 & 32.621 & 17.0078 & .599 & .434 \\
\hline posttest & 29 & 43.0 & 80.0 & 1712.0 & 59.034 & 9.4924 & .357 & .434 \\
\hline $\begin{array}{l}\text { Valid N } \\
\text { (listwise) }\end{array}$ & 29 & & & & & & & \\
\hline
\end{tabular}

Diketahui bahwa nilai skewness pada pretes adalah .602 dan nilai skewness pada posttest adalah .357. Nilai skewness tersebut berada pada interval $|1,0|$ sehingga dapat dianggap data terdistribusi normal. Selanjutnya data tersebut diuji beda dengan menggunakan paired sample t-test.

Berdasarkan data hasil uji $t$-test didapatkan nilai $t$ sebesar 8.314 dengan df 28 , dan nilai signifikansi sebesar 0.00 . Nilai signifikansi tersebut kurang dari 0.50 sehingga dapat disimpulkan bahwa perbedaan nilai pretest dan nilai posttest adalah signifikan. Hal ini dapat diartikan bahwa nilai posttest lebih tinggi daripada nilai pretest.

Berdasarkan hasil uji Paired Samples t-Test diperoleh rata-rata nilai posttest-pretest adalah 26,41 dengan nilai signifikansi 0.00 yang berarti bahwa perbedan nilai pretest dan posttest adalah signifikan. Selanjutnya dilakukan perhitungan untuk mengetahui besarnya pengaruh pretest dan posttest dengan menggunakan $d$-effect size dan didapatkan nilai 1,98 dengan kriteria "Lebih besar seklai dari standar" (Morgan, dkk., 2004) . Kemudian dilakukan uji $n$ gain dan didapatkan nilai rata-rata sebesar 0,46 dengan kriteria "medium atas" (Sutopo, 2014). Tinggi rendahnya nilai $\mathrm{n}$ gain dipengaruhi oleh peningkatan rata-rata pretest ke posttest dari masing- masing soal.

Berdasarkan hasil analisis dapat disimpulkan yaitu pembelajaran dengan menggunakan model pembelajaran Inquiry Argumentati dapat meningkatkan rata-rata pemahaman konsep siswa pada materi pembiasan pada cahaya sebesar 29,2\%. Hasil peningkatan tersebut menunjukkan bahwa model pembelajaran Inquiry Argumentatif efektif untuk meningkatkan kemampuan pemahaman konsep siswa pada materi optik. Hal serupa juga ditemukan pada penelitian Kristianingsih, dkk (2010) dan Umrotun (2012), menyatakan bahwa model pembelajaran inkuiri dapat meningkatkan pemahaman konsep siswa pada materi optik.

\section{Simpulan}

Berdasarkan paparan data dan hasil analisis kualitatif-kuantitatif, diperoleh kesimpulan sebagai berikut :

4.1. Terdapat perbedaan kemampuan pemahaman konsep siswa antara sebelum dan sesudah pembelajaran. Perbedaan prestasi belajar disebabkan oleh siswa yang ikut serta aktif dalam pembelajaran. 
4.2. Peningkatan nilai pretest dan posttest setelah pembelajaran dengan menggunakan model pembelajaran Inquiry Argumentatif sebesar 29,2\%. Hal ini disebabkan keterampilan yang dilatihkan saat menggunakan model Inquiry Argumentatif dapat mengasah kognitif siswa.

\section{Daftar Rujukan}

Aydin, S., Keleş, P. U., \& Haşiloğlu, M. A. (2012). Establishment for misconceptions that science teacher candidates have about geometric optics. The online journal of new horizons in education, 2(3), 7-15.

Creswell, J. W. (2012). Education research: Planning, Conducting and Evaluating Qualitative. Quantitative research. Boston: Pearson.

Debnath, D., Barthakur, N. K., Baruah, R. S., \& Goswami, P. K. (2012). Problems of teaching optics in middle school: A survey in Batadraba education block of Nagaon district, Assam, India. International Journal of Scientific and Research Publications, 2(8), 1-4.

Ellianawati, E., \& Wahyuni, S. (2010). Pemanfaatan model self regulated learning sebagai upaya peningkatan kemampuan belajar mandiri pada mata kuliah optik. Jurnal Pendidikan Fisika Indonesia, 6(1).

Kristianingsih, D. D., Sukiswo, S. E., \& Khanafiyah, S. (2010). Peningkatan hasil belajar siswa melalui model pembelajaran inkuiri dengan metode pictorial riddle pada pokok bahasan alat-alat optik di SMP. Jurnal Pendidikan Fisika Indonesia, 6(1).

Morgan, G. A., Leech, N. L., Gloeckner, G. W., \& Barrett, K. C. (2004). SPSS for introductory statistics: Use and interpretation. Psychology Press.

Osborne, J. (2010). Arguing to learn in science: The role of collaborative, critical discourse. science, 328(5977), 463-466.

Prihatiningtyas, S., Prastowo, T., \& Jatmiko, B. (2013). Imlementasi simulasi PhET dan KIT sederhana untuk mengajarkan keterampilan psikomotor siswa pada pokok bahasan alat optik. Jurnal Pendidikan IPA Indonesia, 2(1).

Saeed, F. (2013). An Innovative Teaching Method for Geometric Optics Using Hands-On Exercises in a Large Classroom Setting to Stimulate Engaged Learning. Optometric Education, 38(2).

Suniati, N. M. S., Sadia, I. W., \& Suhandana, G. A. (2013). Pengaruh implementasi pembelajaran kontekstual berbantuan multimedia interaktif tehadap penurunan miskonsepsi (studi kuasi eksperimen dalam pembelajaran cahaya dan alat optik di SMP Negeri 2 Amlapura). Jurnal Administrasi Pendidikan Indonesia, 4(1).

Waldrip, B. (2014). Impact of a representational approach on students'reasoning and conceptual understanding in learning mechanics. International Journal of Science and Mathematics Education, 12(4), 741-765.

Umrotun, U. (2012). Peningkatan Kemampuan Pemahaman Konsep Optik Melalui Teknik Inkuiri Terbimbing Peserta Didik Kelas VIII Semester Genap Tahun Ajaran 2011/2012. Jurnal Penelitian Pembelajaran Fisika, 3(1).

Wenning, C. J. (2010). Levels of inquiry: Using inquiry spectrum learning sequences to teach science. Journal of Physics Teacher education online, 5(4), 11-20.

Widayanto, W. (2009). Pengembangan keterampilan proses dan pemahaman siswa kelas X melalui kit optik. Jurnal Pendidikan Fisika Indonesia, 5(1). 